\title{
O OUTRO E A SOLIDARIEDADE: UMA ANÁLISE EXISTENCIALISTA DO CISMA ÉTICO NA CONTEMPORANEIDADE
}

\author{
THE OTHER AND SOLIDARITY: AN EXISTENTIALIST ANALYSIS OF THE ETHICAL CISM IN \\ CONTEMPORANITY.
}

Thiago Teixeira*

\begin{abstract}
RESUMO
Embora a solidariedade possa ser confundida com um valor absoluto, assumimos a empreitada de demonstrar como ela pode ser lida no cerne da perspectiva sartriana. Nesse lugar epistemológico, reconhecemos que todos os valores são constituições humanas, pois partem da liberdade, em situação. Demonstraremos, aqui, como o encontro entre os indivíduos é marcado por uma imediatez banal que pode alimentar condutas de má fé ${ }^{1}$ e, por conseguinte, instaurar um ambiente de inautenticidade e de colapso moral. Nossa proposta versa sobre a discussão acerca das relações autênticas e tensionais que, a nosso ver, responderiam o problema do reconhecimento contemporâneo. Inclinamo-nos a demonstrar como o encontro com o outro - enquanto outro - indica uma força na compreensão existencialista humanista de Sartre. Requisitamos, assim, a análise da solidariedade, aos moldes do pensamento sartriano, como escapamento das percepções banais do outro.
\end{abstract}

PALAVRAS-CHAVE: Solidariedade. Valor. Liberdade. Situação.

\begin{abstract}
Although solidarity can be confused with an absolute value, we undertake a task of demonstrating how it can be read without the sartrian perspective. In this place of speech, we recognized that all values are human constitutions, because they depart from freedom, in situation. We will demonstrate here how the encounter between the components and the content by a banal immediacy that can feed bad faith conducts and therefore, establish an environment of inauthenticity and moral collapse. Our proposal for a discussion of authentic and tentative relations, one might say, would respond to the problem of contemporary recognition. We are inclined to show how the encounter with the other - as another - indicates a strength in Sartre's existentialist humanist understanding. We thus require the analysis of solidarity, in the molds of Sartrian thought, as an escape from the banal perceptions of the other.
\end{abstract}

KEYWORDS: Solidarity. Value. Freedom. Situation.

\section{INTRODUÇÃO}

Entre as grandes querelas contemporâneas ressalta-se o desafio ético do reconhecimento. É constante a percepção de que vivemos um cisma moral e, na mesma

\footnotetext{
${ }^{*}$ Mestre em Filosofia pela FAJE. Doutorando em Ciências Sociais pela PUC Minas. Professor do Departamento de Filosofia da PUC Minas. E-mail: thiagoteixeiraf@gmail.com.

${ }^{1}$ Escolhemos a grafia de má fé sem o hífen para acompanhar o texto original sartriano. Ali o termo usado por Sartre é mouvesse foi (SARTRE, 1943, p. 82).
} 
proporção, um colapso nos valores e nas relações. O Existencialismo, para nós, ainda promove, nesse cenário, discussões pertinentes em termos éticos, pois se propõe a pensar o sujeito humano, em processo, no mundo e junto aos outros.

Nosso lugar de discussão está exatamente numa relação triádica: do eu, do outro e da liberdade, como fio condutor desse movimento. Pensamos ser o problema da liberdade a grande questão do Existencialismo. Ela, por sua vez, se desdobra e abarca as discussões no campo da ontologia, da fenomenologia e da ética. Detemo-nos no trânsito entre essas regiões a partir da perspectiva do para-si, como realidade humana situada.

É possível dizer que, no prisma sartriano, o sujeito humano não está sozinho. Além disso, ele é aquilo que realiza de si mesmo. Sua existência acontece num lugar, com um sistema econômico, e uma estrutura de valores definidas. Isso, em contrapartida, não mina a sua liberdade e responsabilidade. O sujeito experimenta a sua liberdade, quando se engaja em sua história, assume o seu tempo e se torna autor dos processos de ressignificação de sua situação. Lemos aqui a solidariedade, não como um valor absoluto, mas como o compromisso de assumir o outro como sujeito e as nossas escolhas com profunda responsabilidade.

O que nos interessa é pensar que essa conduta de vinculação à situação, enquanto engajamento, não acontece no âmbito das formulações abstratas. Queremos dizer que as experiências do homem são concretas e junto aos outros, no mundo. Sendo assim, não há como escapar da exigência que está acoplada ao ser do para-si: o ser para-outro.

A situação comporta também a existência dos outros, e esse é o elemento de alteridade que afeta o exercício da minha liberdade porque, quando entro em relação com outros sujeitos, defontro-me com outras liberdades e com os conflitos que daí possam decorrer. (SILVA, 2011. p. 128, grifo do autor).

Sartre nos apresenta as estruturas mais elementares das relações humanas através de uma descrição minuciosa do encontro entre as liberdades. Ali, o filósofo apresenta as nuances que denotam a ambivalência desse encontro. Podemos inferir que, nesse enfrentamento entre as liberdades, há a possibilidade. Nela, por sua vez, é possível que estejamos ou nos coloquemos na condição de sujeito ou de objeto. "O que encaro constantemente através de minhas experiências são os sentimentos do Outro, as ideias do Outro, as volições do Outro, o caráter do Outro. É, porque, com efeito, o Outro não é somente aquele que eu vejo, mas aquele que me vê." (SARTRE, 2010, p. 297).

Objetiva-se, pois, verificar qual a estrutura do cisma moral que se instaura na contemporaneidade. Incialmente localizamos o problema exatamente ali, na dificuldade em 
perceber em que lugar nós nos colocamos e, além disso, aponta-se a violência que se instaura ao encerrar o outro num lugar subjugado, simplesmente por não aceitar a sua existência, singularidade e diferença.

Lemos no Existencialismo que a história é marcada pela distinção latente entre o Eu, com os seus pares, e o outro, como expressão da diferença. Identificamos que, para Sartre, o grande desafio está em rearticular o lugar da moral e perceber que o outro não é um fim, isto é, um objeto, mas sim a sua liberdade.

Ao reavaliar esse panorama, enfraquecemos a possibilidade de manipular a existência do outro como um objeto, fim de si mesmo. Ao colocar a liberdade como fim, somos inclinados a pensar numa atmosfera radicalmente humana, em que os valores integram e constituem relações que, embora tensionadas, promovem uma moral da ambiguidade. Para iniciar as nossas investigações é preciso que nos perguntemos: o outro é utensílio ou liberdade?

\section{O OUTRO: UTENSÍLIO OU LIBERDADE?}

A liberdade é, sem dúvidas, o fio condutor que transpassa todo $O$ ser e o nada: ensaio de ontologia fenomenológica. As discussões que emergem das modulações daquele pressuposto nos interessam de modo bastante singular. Ao transitarmos pela Ontologia sartriana - sua descrição dos modos de ser — destacamos a realidade de três variações de ser que se justapõem: para-si, em-si e para-outro.

O modo de ser em-si é determinado pela totalidade. Ele, em sua plenitude, é o que frustra o para-si. O para-si, por sua vez, é um desnível no em-si. Enquanto o em-si é pleno e maciço, o para-si - ser da consciência - se descobre faltoso e aberto às possibilidades. Destacamos o desejo do para-si em se tornar em-si, pois a realidade humana encontra dificuldade em lidar com a possiblidade, uma vez que ela exige a escolha e, como sabemos, toda escolha é uma manifestação da angústia como realidade existencial.

Essa tensão entre o ser pleno e o ser da consciência encontra várias nuances no intramundo da filosofia de Sartre. Uma delas está na relação do para-si com o para-outro. Essa dificuldade em lidar com a abertura e a possibilidade ganha força, pois o outro aparece a nós. Sua presença no mundo, como a nossa, é irrevogável e sem desculpas. Mas sabemos lidar, de forma autêntica, com essa presença? 
Podemos inferir que a existência do outro não é mera ilusão, ou uma formulação do conhecimento. O outro não é um conceito. Ele é presença real no mundo e, como nós, é dito por sua liberdade. Estamos no mundo com ele, isto é, habitamos uma situação e, nela, os nossos olhares se entrecruzam. O outro aparece como mediador da minha existência e, na mesma esteira, eu me coloco como uma liberdade que o tenciona. Inicialmente, somos inclinados a pensar que a atitude de recusar a responsabilidade em relação ao outro, ao se esconder na sua redução à condição de objeto, também é má-fé. Esse argumento fica claro quando Sartre diz que,

Diante de uma situação real - por exemplo, o fato de eu ser sexuado, capaz de ter relação com um ser de outro sexo e de ter filhos - eu sou obrigado a escolher uma atitude e, de qualquer modo, sou responsável por uma escolha que, ao me engajar, engaja também a humanidade inteira, mesmo que nenhum valor a priori determine uma escolha. (SARTRE, 2010, p. 51).

Há uma constante apreensão do outro, dado o fato de que ele é no mundo e se constrói numa situação. No entanto, o nosso olhar para esse outro pode ser ambivalente: a) ele pode se deter na "aparição banal" (SARTRE, 2009, p. 328); b) ou ele pode se firmar numa reciprocidade sincera. Inicialmente, compreendemos que ambas as formas têm como pano de fundo a relação tríplice entre o eu, o outro e a liberdade.

Todavia, a primeira modalidade de encontro se firma na vontade de tornar o outro um em-si. A segunda, por sua vez, se estrutura numa modalidade de olhar autêntica e que assume o confronto entre as liberdades, como a forma orgânica da construção de valor.

\subsection{A aparição banal e seus feitos nocivos à ética}

A aparição banal assume o status de uma percepção do outro como objeto. Nela a nossa relação não empreende nenhuma responsabilidade, visto que não há uma reciprocidade ou encontro. Ele aparece à minha consciência, mas na condição de outro-objeto e, nesse ínterim, ele é compreendido como um objeto posicionado pela minha consciência.

\footnotetext{
Estou em um jardim público. Não longe de mim há um gramado e, ao longo deste gramado, assentos. Um homem passa perto dos assentos. Vejo este homem e o capto ao mesmo tempo como um objeto e como um homem. Que significa isso? Que quero dizer quanto afirmo que este objeto é um homem? (SARTRE, 2009, p. 328, grifo do autor).
} 
O filósofo, em a Transcendência do ego (2013), apresenta a consciência como esse movimento de posicionar as coisas no mundo. Lemos ali que a realidade do sujeito ou, se quisermos, o seu ego, não está nele mesmo, mas fora, no mundo. Não há, na perspectiva do existencialista, uma posição de um ego maciço, pronto e acabado. Ao contrário, ele não habita na consciência, mas a distância, no movimento e buscando a si mesmo, no mundo. A consciência está no mundo, ela é concreta, pois se apreende reflexiva, na situação. Conforme também o entendimento de seus comentadores,

O processo de formação da realidade humana, que é a existência, reflete-se na consciência. Nesse sentido, a construção do sujeito é um caminhar na direção de $s i$, e o si é aquilo que está fora da subjetividade, haja vista que a consciência só é quando lançada no mundo. Assim, Sartre denomina de Para-si a constituição da subjetividade como movimento intencional da consciência. (ALMEIDA, 2016, p. 34 , grifos do autor).

Destacamos o fato de que esse processo de constituição de si, a partir do abandono no mundo, pode desembocar numa atitude de má fé. Como é sabido, ela se determina como mentira que se conta a si, a fim de escapar da angústia existencial.

Ela não deseja negar a si, mas ocultar a verdade de alguém. O intuito do mentiroso é o de ser cínico, mas ele não intenta preencher a consciência com a opacidade de um ser em-si, uma vez que não consegue desestruturar a condição de translucidez da consciência presente. Nesse ato fica mantida a estrutura intencional da consciência visando um ser que ela não é, mesmo que isso se dê como ocultação de algo. Compreende-se claramente que o enganador se reconhece enquanto tal. O "falsário" conhece a mentira que oculta, e identifica-se por esta razão a "dualidade ontológica do eu e do outro" (E. N., p. 94). (SASS, 2011, p. 480).

Se a consciência se determina pelo processo de negação, haja vista que é através dela que o homem nadifica o mundo e pode ressignificá-lo, é possível dizer que a má fé é uma forma consciente a qual o homem empreende para, de forma virtual, dar sentido pleno à sua existência. Todavia, esse processo não é apenas subjetivo, visto que é possível posicionar o outro de forma imediata e objetal. Há, nas duas posturas, má fé.

Podemos dizer, então, que ele, o homem, pode querer fazer-se na má fé e, na mesma medida, querer o outro nessa mesma posição. É perceptível o impacto ético dessas duas posições, visto que há, ali, uma manutenção da subjugação. Se, para o outro, sou um objeto e só, não pode haver nessa relação responsabilidade. Ao contrário, se o outro é um objeto para mim, eu também não me responsabilizo por ele, mas eu o uso. É preciso frisar que o termo "uso" aqui se torna referto de um perigo singular. 
O risco está no fato de que o outro é um objeto para mim, isto é, numa visão objetal ele está encerrado nas minhas distâncias. Eu que o posiciono. Desta feita, sou o sujeito que lhe confere sentido, imediatamente. Ele é um objeto iluminado pela minha consciência e, portanto, é designado por ela.

Lemos que essa atitude, embora imediata, pois o outro aparece como presença no mundo, não pode ser permanente se quisermos tratar de uma eticidade. Isto porque, se o outro é posto em referência a nós, quem nos garante que, em longo prazo, esse posicionamento não se transmutará em legitimidade de violência?

O outro ainda é objeto para mim. Pertence às minhas distâncias: o homem está lá, a vinte passos de mim, vira-me as costas. Enquanto tal acha-se a 2, 20m do gramado, a seis metros da estátua; por conseguinte, a desintegração de um universo está contida nos limites deste universo mesmo. (SARTRE, 2009, p. 330).

Destituir o outro, através do olhar, de uma consciência, tem impactos nefastos quando tratamos de um horizonte de eticidade, visto que rompemos com uma estrutura de reciprocidade. Entendemos, também, que essa lógica de reciprocidade não é harmônica, tampouco linear, mas não podemos deixar de frisar nossa compreensão de que mesmo na tensão os sujeitos devem ser vistos uns pelos outros, na sua condição de existente e humano e não como uma existência objetificada.

\section{OUTRO: O SUJEITO QUE ME VÊ}

Para Sartre, o outro, enquanto sujeito, se coloca na posição daquele que nos vê. Nessa estrutura, ele rompe com aquela aparição imediata, como uma dissolução drástica no mundo, para revelar nosso ser-objeto, para nós. Nesse sentido, podemos inferir imediatamente que o outro, enquanto sujeito, nos faz encontrar o nosso lugar de objeto, para a sua consciência.

Há em seu pensamento a demonstração de uma "ligação fundamental" (BORNHEIM, 2000, p. 86), que condiciona o Outro a um dado redutível ao campo gnosiológico que se verifica numa relação entre sujeito e objeto. E isso porque "o Outro é por princípio aquele que me olha”. (SARTRE, 2015, p. 332), e esse olhar é o que torna possível a intermediação do Eu consigo mesmo. O Outro é, assim, o que viabiliza e mesmo exige que Eu possa se identificar como ser-no-mundo, como num processo contínuo de devolução ao outro, quando se pretende encontrar consigo mesmo. (SANTOS, 2011, p. 69, grifo da autora ). 
Não há como negar que tratamos de uma mudança de posição desse olhar e que, em ambas, há uma tentativa de má fé de totalizar o outro. Portanto, há nessa virada de percepção uma tentativa de ser a referência e de desconsiderar o que chamaremos de reconhecimento, isto é, o ato de lidar com outro, na sua diferença, mas resguardando a sua existência.

Nesse sentido, é preciso falar do nosso olhar, visto que ele é o fator que propicia esse encontro. Para Sartre, o olhar manifesta "uma pura remissão a mim mesmo" (SARTRE, 2009, p. 333). Assim, o olhar, ao se lançar no outro, deseja fortemente dizer a si mesmo. O que interessa aqui é dizer que somos os nossos atos. Sendo assim, não somos nada antes que nos façamos. Essa é uma das máximas do Existencialismo.

Se, portanto, nos fazemos ao olhar do outro e, mais, se nessa relação nos constituímos, é preciso converter essa estrutura para além de uma perda hemorrágica de sentido na percepção. Para nós, não se trata apenas de uma descrição ontológica e fenomenológica do movimento da consciência e da percepção em relação ao outro, mas de uma requisição fática da existência de alguém para além de nós. Pensamos na importância de grifar que os nossos atos o afetam drasticamente. Além disso, podemos dizer que essa tentativa oscilante de determinar ou ser determinado é virtual e, além disso, se detém numa conduta de má fé.

A objetivação do outro é marca fundamental de nossa percepção imediata. O que nos interessa pensar é o que está para além dessa imediatez. Logo, somos inclinados a problematizar o plano da facticidade, isto é, o lugar onde habitamos junto aos outros. Nesse sentido, destacamos o risco que tangencia a alteridade, em Sartre. Nela há a possibilidade de um "apelo, mas também uma possível fonte de alienação" (CASTRO, 2016, p. 76).

O conflito que se instaura entre o eu e o tu, para nós, dispõe de uma ambiguidade, como boa parte das questões que se apresentam no cerne da filosofia sartriana. Somos constantemente levados a pensar no campo da ética como um horizonte pleno, no qual os valores estão dados e, com uma simetria ímpar, resolvem todas as questões da ordem objetiva.

Aqui está a grande questão: será mesmo que pensar o valor moral, para além do humano, faz com que se possa instaurar uma ordem humana? Se, por um lado, questionamos o fato de que as grandes bases éticas se sustentam em paradigmas metafísicos, de outro, atestamos que Sartre se coloca para além daquela disposição e do sincronismo dos valores absolutos. Até mesmo porque eles se apresentam como recusa à liberdade e, portanto, condições de má fé.

O conflito, isto é, o confronto entre as liberdades, desponta como uma potencialidade no que tange às discussões éticas. Inclusive, se torna relevante mapear e compreender as 
diferenças no cenário contemporâneo. Pensamos que a tentativa de homogeneizar o problema da alteridade culminou no que podemos ver hoje como o seu colapso ético. Buscamos o tempo todo que o outro seja o mesmo, e isso tem impactos significativos na vivência cotidiana, bem como nos desafios éticos a que somos submetidos.

\title{
2.2 O OUTRO E SUA SUBJETIVIDADE
}

Estamos de acordo com a ideia de que a relação com o outro é marcada por uma tensão. Todavia, ela também apresenta uma marca fundamental: a responsabilidade. Nessa constante ação de existir, nós e os outros somos acometidos por uma ambiguidade profunda. O compromisso com o outro, assim como a liberdade, se apresenta como uma condenação, pois somos lançados na nossa situação e, do mesmo modo, habitamos nela, com os outros. Nesse sentido, o outro é aquele

\begin{abstract}
Que me entrega o que sou como não revelado, mas sem revelar-se a si mesmo; aquele que está presente enquanto me visa e não enquanto é visado é o polo concreto e fora de alcance de minha fuga, da alienação e dos meus possíveis e do fluir do mundo rumo ao outro mundo, mundo este que é o mesmo e, contudo, incomunicável com aquele [...] Se estou totalmente entregue à minha vergonha, por exemplo, o é a presença imensa e invisível que sustenta esta vergonha e a envolve por todo lado. (SARTRE, 2009, p. 346, grifos do autor).
\end{abstract}

Ele, o outro, está diante de mim. Ele vivencia a mesma situação que eu, embora nossos projetos sejam distintos e marcados por escolhas diferentes. No interior dessa multiplicidade dos projetos e deliberações há algo comum: somos responsáveis pelo que realizamos, nesse mesmo mundo. Por isso, é preciso reavaliar o que chamamos aqui de subjetividade e, mais, salientar a sua dimensão concreta, situada e responsável.

Há um erro comum em pensar que o Existencialismo é uma filosofia do desespero, bem como uma compreensão do mundo que se centraliza no sujeito. O risco está em ler essa escola filosófica assumindo como regra uma dimensão egoica, subjetivista e solipsista.

O sujeito para Sartre é, de fato, responsável pelo que faz de si. Como sabemos, o Existencialismo declara que o sujeito é aquilo que empreender de si mesmo. Contudo, esse movimento é sempre um lançar-se no mundo. O mundo, por sua vez é habitado por outros sujeitos. Assim, fica claro que a subjetividade, em Sartre, não denota subjetivismo, tampouco é marca de uma filosofia do indivíduo solitário. 
Se sou um operário e escolho aderir a um sindicato cristão em vez de ser comunista, se, por esta adesão, eu quero indicar que a resignação é, no fundo, a solução que convém, e que o reino do homem não se dá nesta terra, eu não estou decidindo apenas meu caso particular: eu quero resignar-me por todos, consequentemente, minha escolha envolve a humanidade inteira. E se quero algo mais individual, casarme e ter filhos, embora este casamento dependa unicamente de minha situação, ou de minha paixão, ou de meu desejo, com isso eu estou envolvendo não apenas a mim, mas a toda a humanidade na prática da monogamia. Assim, sou responsável por mim e por todos e crio determinada imagem do homem que escolho ser; ao escolher a mim, estou escolhendo o homem. (SARTRE, 2010, p. 28).

Escolher a si mesmo enquanto projeto, no mundo, é, ao mesmo tempo, escolher aos outros. Pensamos que essa escolha pode desembocar em dois caminhos: a) podemos escolher a nós mesmos e aos outros assumindo a nossa liberdade e angústia, ou podemos nos esquivar daquela angústia, nos submetendo ou submetendo outrem à condição de objeto. Nesse último caso, está posto o enquadramento de violência e subjugamento que permearia as relações, para além daquela tensão originária.

Ao escaparmos dessa responsabilidade, isto é, na tentativa de nos percebermos apartados da história, da facticidade e, por conseguinte, da responsabilidade em relação aos valores, nos alinhamos a uma conduta de má fé. Nesse sentido, ela se manifesta em “qualquer tentativa de nos absorvermos completamente em nossa facticidade" (REYNOLDS, 2013, p. 110) sem que assumamos a dimensão de ultrapassamento dessa situação. Obliterar a responsabilidade e requisitar valores petrificados em relação a si e aos outros.

Podemos dizer que essa escolha toma forma quando a compreendemos como engajamento. Este, por sua vez, é a consolidação de um horizonte marcado por indivíduos que tomam consciência de sua responsabilidade. Para Sartre, somos delineados pelas escolhas de nossos fins, isto é, a nossa situação não é engessada.

Observa-se que, ao dissertar sobre a busca pelos fins, Sartre deixa claro que nós a realizamos em todos os instantes desse caminho, enquanto projeto existencial em processo. Ela marca as relações entre os indivíduos, bem como as relações puramente espaciais (SARTRE, 2009, p. 607). Atribuímos valor no encontro com o outro, ao reavaliar a situação e, também, quando ressignificamos o espaço no qual existimos.

Nela, isto é, na situação, nos construímos. Atribuímos, a ela e a nós, valor. Nesse contexto, nosso afetar o outro é, também, parte dessa adesão por um fim. É preciso, então, nesse cenário tão controverso em que estamos, nos perguntar: de que modo me coloco e, também, ao outro como fim, liberdade ou objeto? 
No prisma de Sartre, se nos ativermos ao sentido corriqueiro do termo responsabilidade, veremos que ele se alinha ao primeiro tipo de fim que colocamos na questão acima. Ser responsável, então, indica assumir que se é "autor incontestável de um acontecimento" (SARTRE, 2009, p. 678).

Se o sujeito humano é autor inconteste de seus fins, logo preciso criticar quais sãos os fins que nos tornam mais humanos. E, na mesma medida, quais são os valores que integram e consolidam uma moral correspondente a um universo no qual a liberdade é marca aparente nas relações.

\begin{abstract}
A liberdade é para Sartre a condição indispensável e fundamento da ação. De fato, toda ação implica para a consciência a possibilidade permanente de operar uma ruptura com o seu próprio passado. Contrariamente às abordagens da Sociologia e da Psicologia empíricas, a ação não é provocada por uma causa necessária anterior. Toda ação é afirmação de um sentido, é intencional [...] a ação é autocriação. (PFIEL, 2008, p. 154, grifo do autor).
\end{abstract}

É notória a relação que se pode estabelecer entre engajamento e generosidade, em Sartre. A querela sobre esse último conceito aparece, com afinco, nos Cadernos por uma moral. Para Sartre, os valores que devemos construir e erigir se alinham à busca pela libertação dos homens e mulheres, isto é, uma moral, para ser concreta, deve empreender valores que se esforçam para romper a lógica da violência e da opressão.

A generosidade é definida como um tipo de consentimento lúcido ao tornar-se em si
de toda livre iniciativa, o qual se distingue do estoicismo e de resignação em razão
do engajamento que ela produz. [...] na relação com o outro a generosidade consiste
em captar o ser-no-mundo, na sua parte de finitude, de facticidade e de fragilidade.
O reconhecimento do outro e de sua fragilidade não significa tomá-lo por fim. Em
uma entrevista feita em 1949, Sartre afirma: "Se tomo objetivamente por fim a
liberdade do outro, eu lhe faço violência. Mas se tomo a minha própria liberdade por
fim, ela provoca a exigência de tratar os outros como liberdade." (CASTRO, 2016,
p. 231, grifo do autor).

Parece-nos que Sartre indica a generosidade como um valor importante. É preciso, contudo, entender que não se trata de um valor absoluto, em si mesmo ou romântico. Entendemos que ela, no encontro com o outro, designa a construção de um horizonte humano, aberto e que assume o fracasso como terreno de constituição. Pensamos que compreender a responsabilidade associada à nossa liberdade nos lança na percepção do outro como outro, diferente. Além disso, constatar que a sua diferença não o faz menos sujeito. 
Talvez seja essa uma das maiores demandas da contemporaneidade: romper com a lógica e o olhar em relação ao outro; assim, abrir-nos à perspectiva na qual ele, o outro, aparece como sujeito. Pensamos ser urgente a constituição de um horizonte no qual a diferença - que aparece da existência do outro - faça com que nós, generosamente, sintamos a necessidade de consolidar uma moral que escuta, que respeita e situa a todos, em suas demandas, peculiaridades e necessidades, num terreno radicalmente humano e, por isso, diverso.

\section{CONCLUSÃO}

Frente ao cenário de drástica violência marcado pela intolerância em nosso dia a dia, vale colocar em evidência todos os pressupostos apresentados até aqui. Acreditamos, sinceramente, que o existencialismo sartriano, não se pretende como a solução para os grandes desafios contemporâneos, mas promove questionamentos pertinentes para o problema do cisma ético, a partir da discussão sobre a alteridade.

Pensamos que a estrutura de uma alteridade negativa, isto é, da tensão entre as liberdades, corresponde ao mapeamento das grandes querelas que nos cercam. Todavia, pensamos que o sujeito contemporâneo tem permanecido no que chamamos, neste trabalho, orientados por Sartre, de "apreensão banal" do outro.

Nesse contexto, as relações têm se encerrado na apreensão do outro como objeto, e só. Lemos a grande dificuldade de compreender a outridade e, em consequência, a sua possibilidade e liberdade. Nosso desejo permanente de fugir da angústia tem marcado as nossas relações. Ora nos submetemos, noutro momento assumimos a posição de subjugados, simplesmente por não assumir a angústia como marca fundamental da existência humana.

É preciso que tomemos consciência de nossa liberdade. Ainda nessa linha de raciocínio, prestar atenção na responsabilidade que se engranza à própria existência. Chegamos à conclusão de que existir é instaurar fins através de nossas escolhas. Talvez seja urgente que nossos valores escolhidos integrem a todos no cenário de reconhecimento.

Estamos diante de uma questão muito pertinente e, mais, que acompanhou toda a discussão travada até aqui: quais são os riscos de rebaixar o outro à condição de objeto? Estamos de acordo que a manutenção das violências se dá nessa estrutura. Podemos dizer que é possível uma moral que se sustenta na tensão, mas que se torna inviável uma existência ética 
que se sustenta na reprodução perversa de violências que, de tão estruturais, colocam "naturalmente" nós e os outros no campo do manipulável.

\section{REFERÊNCIAS}

ALMEIDA, Silvio Luiz. Sartre: direito e política. São Paulo: Boitempo, 2016.

CASTRO, Fábio Caprio Leite. A ética de Sartre. São Paulo: Loyola, 2016.

PFIEL, Luis Cláudio. A moral em Sartre: uma porta para o possível. In: CESAR, Marcondes Constança; BULCÃO, Marly (org.). Sartre e seus contemporâneos. Ética, racionalidade e imaginário. São Paulo: Ideias \& Letras, 2008. p. 147-160.

REYNOLDS, Jack. Existencialismo. Tradução de Cesar Souza. Petrópolis: Vozes, 2013.

SANTOS, Magda Guadalupe dos. Alteridade, Facticidade e igualdade: leituras de Sartre, Beauvoir e Levinas no processo de radicalização da Metafísica no século XX. In: OLIVEIRA, Ibraim Vitor de; SANTOS, Magda Guadalupe dos (org.). Tempos da metafísica. Belo Horizonte: Tessitura, 2011, p. 53-93.

SARTRE, Jean-Paul. A transcendência do ego: esboço de uma descrição fenomenológica. Tradução de João Batista Kreuch. Petrópolis: Vozes, 2013.

SARTRE, Jean-Paul. Cahiers por une morale. Paris: Gallimard, 1983.

SARTRE, Jean Paul. O existencialismo é um humanismo. Tradução de João Batista Kreuch. Petrópolis: Vozes, 2010.

SARTRE, Jean Paul. O ser e o nada: ensaio de ontologia fenomenológica. 18. ed. Tradução de Paulo Perdigão. Petrópolis: Vozes, 2009.

SASS, Simeão Donizeti. O problema da totalidade na ontologia de Jean-Paul Sartre. Uberlândia: EDUFU, 2011.

SILVA, Franklin Leopoldo e. O conhecimento de si. Rio de Janeiro: Casa do Saber, 2011. 